\title{
Kappa Light Chain to Lambda Light Chain Ratio Measurement
}

National Cancer Institute

\section{Source}

National Cancer Institute. Kappa Light Chain to Lambda Light Chain Ratio Measurement. NCI Thesaurus. Code C161351.

The determination of the ratio of kappa light chain compared to lambda light chain present in a sample. The measurement may be expressed as a ratio or percentage. 